\title{
Uluslararası Finansal Raporlama Standartları 10 Kapsamında Konsolidasyona Geçişin Firmaların Hisse Senedi Getirisi Üzerindeki Etkisi*
}

\author{
Turgut ÇÜRÜK ** \\ Ayşe TANYERİ ${ }^{* * *}$
}

\begin{abstract}
ÖZET
Türkiye'de borsada işlem gören ve grup bazında değerlendirilen firmalar, 2005 yılından itibaren Uluslararasi Muhasebe Standartlarl/Uluslararası Finansal Raporlama Standartlarl (UMS/UFRS) ile uyumlu ulusal muhasebe ve finansal raporlama standartlarına göre konsolide finansal tablo hazırlayıp sunmaktadırlar. Literatürdeki çalışmalar doğrultusunda, Türkiye'de borsada işlem gören firmaları baz alan bu çalışmada, konsolidasyona geçişin firma getirisi üzerindeki etkisi araştırılmıştır.

UFRS 10'a göre düzenlenen konsolide finansal tabloların firma getirisi üzerine herhangi bir etkisinin olup olmadığını araştırmak amacıyla, hisse senedi getirisi ile finansal oranlar arasındaki ilişki literatürde yaygın olarak kullanılan Rasyo Modeli (Bayrakdaroğlu, 2012; Büyükşalvarcı ve Uyar, 2012) esas alınarak analiz edilmiştir. Konsolidasyon öncesi (2000-2003), sonrası (2006-2009) ve bu çalışmanın yapıldiğı son dönem (2012-2015) bazında dörder yıllık periyotları kapsayan, Borsa İstanbul'da işlem gören firmalardan elde edilen veriler regresyon analizi ile test edilmiştir. Araştırma sonuçları, konsolidasyona geçişin önemli olduğuna ve konsolidasyon sonrası finansal oranların firma getirisini açıklama düzeyinde önemli değişiklikler meydana geldiğine işaret etmektedir.

Anahtar Kelimeler: Konsolidasyon, finansal tablolar, finansal tablolar analizi.

JEL Sinıflandırması: M40, M41, M49.
\end{abstract}

\section{The Impact Of Transition To Consolidation Under International Financial Reporting Standards 10 On Stock Returns Of Firms}

\section{ABSTRACT}

Group firms listed on the İstanbul Stock Exchange in Turkey have been preparing consolidated financial statements in line with the rules set at International Accounting Standards/International Financial Reporting Standards (IAS/IFRS) since 2005. This study, focusing on the firms registered with stock exchange in Turkey, attempts to investigate the impact of transition to consolidated financial statements on stock returns of firms.

This study, which seeks find out whether consolidated financial statements prepared in accordance with IFRS 10 have an impact on stock returns of firms or not, analysed the relationship between financial rations and stock returns of firms, by using the Ratio Model (Bayrakdaroğlu, 2012; Büyükşalvarcl ve Uyar, 2012) which commonly used in literature. The data gathered from financial statement of the firms listed on the Istanbul Stock Exchange, covering the four years periods (four years pre-consolidation (2000-2003), four years postconsolidation (2006-2009) and four years the last period of this study (2012-2015)) were tested by running regression analysis. The results show that the level of relationship between financial rations and stock returns of firms changed significantly after consolidation.

Keywords: Consolidation, financial statements, financial statement analysis.

Jel Classification: M40, M41, M49.

\footnotetext{
* UFRS 10'dan adapte edilen TFRS 10 ile Türkiye'de halka açık grup şirketlerince konsolide finansal tabloların düzenlenmesi 2005 yılında zorunlu hale gelmiş olup, bu çalışmada "konsolidasyona geçiş kavramı" konsolide finansal tablo düzenleme zorunluluğu getirilen 2005 dönemini ifade etmektedir. TFRS 10'un çeviri yoluyla UFRS 10'dan adapte edilmiş olması nedeniyle, bu çalışmada esas standart olan UFRS'nin kullanılması tercih edilmiştir.

** Prof. Dr. Turgut ÇÜRÜK, Çukurova Üniversitesi İktisadi ve İdari Bilimler Fakültesi, tcuruk@cu.edu.tr

**** Arş. Gör. Ayşe TANYERİ, Çukurova Üniversitesi İktisadi ve İdari Bilimler Fakültesi, atanyeri@cu.edu.tr
} 


\section{GİRIŞ}

UMS/UFRS’yi diğer muhasebe standartlarından farklı kılan en belirgin özellikleri, ilke bazlı standartlar olması, şeffaflık, gerçeğe uygun değer anlayışı, kapsamlı gelir kavramı ve konsolidasyon uygulaması olarak ifade etmek mümkündür (Blanchette vd., 2011: 15). UMS/UFRS, vergi kanunlarından farklı uygulamaları ve sermaye piyasaları odaklı bir anlayışı benimsemesi sebebiyle finansal tablo kalemlerinin doğru değerlenmesi ve gösterimi için gerçeğe uygun değerleme yöntemini esas alan bir uygulama olduğu için, Avrupa ülkelerindeki muhasebe ve raporlama anlayışını değiştirmiştir. Böylece, Avrupa Birliği (AB) sermaye piyasalarında işlem gören firmaların, 2005 yılından itibaren finansal tablolarını UMS/UFRS'ye göre hazırlayıp sunmalarının zorunlu hale getirilmesi finansal tabloları önemli derecede etkilemiştir.

Sermaye piyasalarındaki gelişmeler, firma birleşmelerinin artması ve çok ortaklı uluslararası yatırımların yaygınlaşması ile birlikte, yatırımcılar başta olmak üzere finansal tablolardan fayda sağlayacak bilgi kullanıcılarına ihtiyaca uygun, doğru, anlaşılabilir, karşılaştırılabilir ve kaliteli finansal bilgiler sağlamak amacıyla konsolide finansal tabloların düzenlenmesi ekonomik bir zorunluluk olarak ortaya çıkmıştır. Grup işletmeler (ana işletme ve bağlı ortaklıklardan oluşan ekonomik birliktelik) tarafından zorunlu olarak UFRS 10'a göre hazırlanan konsolide finansal tabloların, finansal bilgi kullanıcılarının farklı amaçlar doğrultusunda alacakları kararlarda dikkate aldıkları finansal oranları değiştirip değiştirmediğinin araştırılması önemli hale gelmiştir (Akgün, 2012: 1-16).

Yasal zorunluluk olmaması nedeniyle, 2005 öncesi yalnızca gönüllülük temelinde oldukça sınırlı sayıdaki firmalarca konsolide finansal tablolar düzenlenmekte iken, konsolide finansal tabloların düzenlenmesinin halka açık şirketlerce zorunlu hale geldiği 2005 sonrası, piyasayı yansıtan ve kullanıcıların alacakları ekonomik kararları etkileyecek finansal bilginin sunulması ve sermaye piyasalarının etkinliğini arttırmak önem kazanmıştır. Bunun yanı sıra, konsolide finansal tabloların UFRS 10'a göre düzenlenmesi ile birlikte, finansal tabloların analizinde ve dünya çapında sermaye piyasalarında işlem gören firmaların hisse senetlerinin değerlendirilmesinde daha doğru sonuçların elde edilmesi amaçlanmaktadır. Bu bağlamda, grup işletmelerin konsolide finansal tablo düzenleme zorunluluğunun firmaların hisse senedi getirisine herhangi bir etkisinin olup olmadığını ortaya koymak önemli hale gelmiştir.

Grup işletmeler bazında değerlendirildiğinde, konsolidasyona geçiş ile birlikte, grup işletmelere yönelik analizlerde kullanılan finansal oranların hisse senedi getirilerini açıllamadaki etkisinden söz etmek mümkündür.

\section{TEORIK TARTIŞMALAR}

UMS/UFRS'ye geçişin sermaye piyasalarının etkinliğinin artması gibi birçok dolaylı ekonomik etkisinin yanı sıra, aslında sağlamış olduğu tek etkisi değişen finansal tablolar olmuştur (Hung ve Subramanyam, 2007: 624). Konsolidasyona geçiş ile birlikte, finansal tabloların analizinde ve hisse senetlerinin değerlendirilmesinde daha doğru sonuçların elde edilmesi beklenmektedir. Finansal tabloların analiz edilmesinde kullanılan en yaygın yöntemlerden birisi, firmaların finansal tablolarından elde edilen bilgiler aracıllı̆ıyla hesaplanan finansal oranlarla yapılan, literatürde rasyo veya oran analizi tekniği olarak ifade edilen analiz tekniğidir. Bu sebeple, çalışmada finansal oranlar kullanılarak konsolidasyona 
geçişin Borsa İstanbul (BIST)'da işlem gören firmaların hisse senedi getirisinde herhangi bir etkisinin olup olmadığının araştırılması amaçlanmıştır.

Literatürde UFRS 10 kapsamında konsolidasyona geçişin hisse senedi getirisine etkisinin değerlendirilmesinde, firmaların hisse senedi getirisini etkilemesi muhtemel değişken olarak finansal oranların kullanıldığı çalışmalara rastlamak mümkündür. Konsolidasyona geçişin hisse senedi getirilerine etkisini analiz etmek için, literatürdeki çalışmalardan da yola çıkarak firmaların hisse senedi getirileri ile finansal oranlar arasındaki ilişki Rasyo Modeli ile analiz edilmiştir (Büyükşalvarcı ve Uyar, 2012; Bayrakdaroğlu, 2013; Sultanoğlu, 2014; vb. gibi). UFRS 10 kapsamında konsolidasyona geçişin etkisiyle ilgili olarak yapılan çalışma sonuçları değerlendirildiğinde, konsolidasyona geçiş ile birlikte finansal oranlardaki değişimin hisse senedi getirisine yansımasında hem olumlu hem de olumsuz sonuçların meydana geldiği görülmektedir (Hung ve Subramanyam, 2007; Callao vd., 2007; Ataman ve Özden, 2009; Gastón vd., 2010; Blanchette vd., 2011; Büyükşalvarc1 ve Uyar, 2012; Sultanoğlu, 2014; vb. gibi).

Literatürdeki anılan farklı çalışma sonuçları, UFRS 10 kapsamında konsolidasyona geçişin firmaların hisse senedi getirisi üzerindeki etkisinin her zaman olumlu ya da her zaman olumsuz olarak gerçekleşeceğini söylemenin imkansız olduğunu göstermektedir. Diğer taraftan, bu zit sonuçların oluşması bize, hisse senedi getirilerini etkileyebilecek başka değişkenlerin de mevcut olabileceğini göstermektedir.

UFRS 10 kapsamında konsolidasyona geçişin firmaların hisse senedi getirisi üzerindeki etkisini değerlendirmeye yönelik Türkiye' deki çalışma sayısının sınırlı olmasından dolayı, bu çalışmanın odak noktasını Türkiye'de BIST’te işlem gören işletmeler oluşturmaktadır.

\section{ARAŞTIRMA YÖNTEMI}

Konsolidasyonun yatırımcılar açısından finansal tablolar analizi üzerine etkisinin olup olmadığını ortaya koymak amacıyla, bu çalışmada alternatif formatta oluşturularak test edilen hipotez;

$\mathrm{H}_{0}$ : UFRS 10 kapsamında konsolidasyona geçiş sonrası finansal oranların hisse senedi getirisini açılama düzeyinde bir değişiklik olmamıştır.

$\mathrm{Bu}$ hipotezi test etmek için; örnek olarak seçilmiş borsada işlem gören firmaların yıllık finansal bilgileri elde edilmiş, bu firmaların hisse senedi getirileri (bağımlı değişken) ile yıllık finansal tablolarından elde edilen finansal oranlar (bağımsız değişken) aracılığıyla modeller oluşturulmuş ve konsolidasyonun etkisini ifade etmek amaciyla pooled regresyon analizi ile hipotez test edilmiştir.

\section{4. ÖRNEKLEM SEÇIMI VE DÖNEMI}

Çalışmanın ana kütlesini BIST'te 2000-2015 yılları arasında işlem gören, 2005 yılına kadar bireysel (Tekdüzen Muhasebe Sistemi'ne göre), 2005 y1lından sonra ise konsolide finansal tablo (TFRS 10’a göre) düzenleyen firmalar oluşturmaktadır. Diğer taraftan, bankalar, finans ve sigorta şirketleri muhasebe uygulamalarındaki farklılıktan dolayı araştırma 
kapsamına dahil edilmemiştir. $\mathrm{Bu}$ nitelikleri taşıyan firmalar arasından rastgele örneklem yoluyla seçilen 48 işletme bu çalışmanın örneklemini oluşturmaktadır.

Çalışmanın kapsadığı dönem konsolidasyon öncesi ve sonrası ile bu çalışmanın yapıldığı 4 yıllık dönemi kapsayan 2000-2015 arası dönemdir. Bu dönemler arasında enflasyon muhasebesinin uygulandiğ zorunluluğunun başladığ yıl olan 2005 yılı araştırmanın kapsamına dahil edilmemiştir. Sonuç olarak, 2000-2003 dönemi konsolidasyon öncesi dönem, 2006-2009 dönemi konsolidasyon sonrası dönem ve 2012-2015 dönemi ise bu çalışmanın yapıldığı son dönem olarak belirlenmiştir.

Özetle, bu çalışmada 48 işletmeye ait 12 yıllık (konsolidasyon öncesi 4 yıl, konsolidasyon sonrası 4 yıl ve bu çalışmanın yapıldığı son dönem olan 4 yıl) döneme ilişkin toplam 576 firma/yıl (48 firma x 12 y1l) verisi analiz edilmiştir.

\section{ARAŞTIRMADA KULLANILAN MODEL VE VERILERİN ANALIZİ}

Konsolidasyonun etkisini ölçmeye yönelik oluşturulan hipotezi test etmek amaciyla, hisse senedi getirileri ile finansal oranlar arasındaki ilişki Rasyo Modeli kullanılarak test edilmiştir. Çalışmada kullanılan model aşağıdaki gibidir;

$$
R_{i t+1}=\beta_{0}+\beta_{1}{ }^{*} r 1_{i t}+\beta_{2}{ }^{*} r 2_{i t}+\beta_{3}{ }^{*} r 3_{i t}+\beta_{4}{ }^{*} r 4_{i t}+\beta_{5}{ }^{*} r 5_{i t}+\varepsilon_{i t}
$$

Burada;

$r 1_{i t}=$ İşletmenin kısa vadeli yabancı kaynaklar/toplam aktif oranı,

$r 2_{i t}=$ İşletmenin toplam borç/öz kaynak oranı,

$r 3_{i t}=$ İşletmenin ROA oranı,(ROA: Net Kâr/Ortalama Toplam Aktif)

$r 4_{i t}=$ İşletmenin cari oranı,(Cari Oran: Dönen Varlıklar/Kısa Vadeli Yabancı Kaynaklar)

$r 5_{\text {it }}=$ İşletmenin asit test oranını (Asit Test Oranı: Dönen Varlıklar-Stoklar/Kısa Vadeli Yabancı Kaynaklar) ifade etmektedir.

Araştırmada hisse senedi getirisi “ortalama değer” olarak dikkate alınmıştır. Ortalama hisse senedi getirisi, $\mathrm{t}+1$ dönemdeki (finansal tabloların yayınlandığı tarihi takip eden yıl) Nisan ayı içerisindeki hisse senedi getirilerinin ortalamasını ifade etmektedir. Belirli bir tarihteki hisse senedi getirileri yerine belirli bir periyottaki hisse senedi getirilerinin kullanılmasının sebebi, getirilerde meydana gelen günlük dalgalanmaları bertaraf etmektir.

Çalışmada, Rasyo Modeli'nde bağımlı değişken olarak tanımlanan hisse senedi getirileri ile bağımsız değişken olarak tanımlanan finansal oranlar arasındaki ilişkiyi test etmek amacıyla, bütünleşik regresyon analizi (pooled regression analysis) kullanılmıştır.

Araştırmadaki işletmelerin 2000-2015 dönemine ilişkin verileri bir finansal veri seti programı olan Finnet 2000 Plus programı (www.finnet.com.tr) aracılı̆̆ 1 ile elde edilmiş olup, 
bu verileri analiz etmek için oluşturulan Rasyo Modeli IBM SPSS Statistics 20 paket program aracılığı ile test edilmiştir.

\section{ARAŞTIRMA BULGULARI}

Çalışmada, konsolidasyona geçişin firmaların hisse senedi getirisine etkisini test etmek amaciyla Rasyo Modeli, 2000-2003 (konsolidasyon öncesi dönem), 2006-2009 (konsolidasyon sonrası dönem), 2012-2015 (bu çalışmanın yapıldığı son dönem) dönemleri bazında ayrı ayrı ve dönemler kendi arasında ikişerli olarak analizler gerçekleştirilmiştir.

Rasyo Modeli’nin 2000-2003, 2006-2009 ve 2012-2015 dönemlerine ilişkin analiz sonuçları Tablo 1'de sunulmuştur;

Tablo 1. Ayrı Ayrı Dönemler Bazında Rasyo Modeli Regresyon Analizi Sonuçları

\begin{tabular}{|c|c|c|c|c|}
\hline \multirow{2}{*}{\begin{tabular}{|l} 
2000-2003 \\
Değişken
\end{tabular}} & \multicolumn{4}{|c|}{$R_{i t+1}=\beta_{0}+\beta_{1}{ }^{*} r 1_{i t}+\beta_{2}{ }^{*} r 2_{i t}+\beta_{3}{ }^{*} r 3_{i t}+\beta_{4}{ }^{*} r 4_{i t}+\beta_{5}{ }^{*} r 5_{i t}+\varepsilon_{i t}$} \\
\hline & Katsayı & VIF & t değeri & t Sig. \\
\hline$\beta_{0}$ & \multicolumn{2}{|l|}{95,570} & 8,658 & 0,000 \\
\hline r1 & $-0,138$ & 1,852 & $-1,142$ & 0,255 \\
\hline r2 & 0,000 & 1,144 & 0,534 & 0,594 \\
\hline r3 & 0,436 & 1,446 & 2,866 & 0,005 \\
\hline $\mathrm{r} 4$ & $-0,471$ & 7,254 & $-0,523$ & 0,602 \\
\hline r5 & $-0,191$ & 7,161 & $-0,169$ & 0,866 \\
\hline F Değeri & \multicolumn{4}{|l|}{$\begin{array}{l}23,560 \\
(0,000)^{*}\end{array}$} \\
\hline $\mathbf{R}^{2}$ & \multicolumn{4}{|l|}{0,527} \\
\hline Adj. $\mathbf{R}^{2}$ & \multicolumn{4}{|l|}{0,505} \\
\hline 2006-2009 & \multicolumn{4}{|c|}{$R_{i t+1}=\beta_{0}+\beta_{1}{ }^{*} r 1_{i t}+\beta_{2}{ }^{*} r 2_{i t}+\beta_{3}{ }^{*} r 3_{i t}+\beta_{4}{ }^{*} r 4_{i t}+\beta_{5}{ }^{*} r 5_{i t}+\varepsilon_{i t}$} \\
\hline Değişken & Katsayı & VIF & t değeri & t Sig. \\
\hline$\beta_{0}$ & \multicolumn{2}{|l|}{52,959} & 8,717 & 0,000 \\
\hline r1 & $-0,197$ & 2,163 & $-2,218$ & 0,028 \\
\hline r2 & $-0,002$ & 1,598 & $-0,195$ & 0,845 \\
\hline r3 & 0,125 & 1,466 & 1,332 & 0,185 \\
\hline $\mathrm{r} 4$ & $-2,191$ & 6,630 & $-1,843$ & 0,067 \\
\hline r5 & 3,153 & 6,515 & 2,177 & 0,031 \\
\hline \multirow[t]{2}{*}{ F Değeri } & \multicolumn{4}{|l|}{12,444} \\
\hline & \multicolumn{4}{|l|}{$(0,000)^{*}$} \\
\hline $\mathbf{R}^{2}$ & \multicolumn{4}{|l|}{0,384} \\
\hline Adj. $R^{2}$ & \multicolumn{4}{|l|}{0,353} \\
\hline 2012-2015 & \multicolumn{4}{|c|}{$R_{i t+1}=\beta_{0}+\beta_{1}{ }^{*} r 1_{i t}+\beta_{2}{ }^{*} r 2_{i t}+\beta_{3}{ }^{*} r 3_{i t}+\beta_{4}{ }^{*} r 4_{i t}+\beta_{5}{ }^{*} r 5_{i t}+\varepsilon_{i t}$} \\
\hline
\end{tabular}




\begin{tabular}{lllll}
\hline Değişken & Katsayı & VIF & t değeri & t Sig. \\
\hline$\beta_{0}$ & 12,704 & & 2,506 & 0,013 \\
\hline r1 & $-0,264$ & 1,702 & $-3,963$ & 0,000 \\
\hline r2 & $-0,006$ & 1,320 & $-0,002$ & 0,998 \\
\hline r3 & 0,000 & 1,066 & $-0,035$ & 0,972 \\
\hline r4 & $-1,328$ & 14,006 & $-0,628$ & 0,531 \\
\hline r5 & 1,177 & 13,583 & 0,463 & 0,644 \\
\hline F Değeri & 5,241 & & & \\
& $(0,000)^{*}$ & & & \\
\hline $\mathbf{R}^{\mathbf{2}}$ & 0,207 & & & \\
\hline Adj. $\mathbf{R}^{2}$ & 0,167 & & & \\
\hline
\end{tabular}

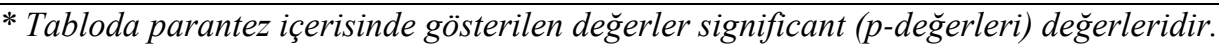

Konsolidasyona geçişin firma performansı üzerindeki etkisine yönelik Tablo 1'deki analiz sonuçlarından $F$ değerleri ve Düzeltilmiş $\mathrm{R}^{2}$ değerleri özet olarak Tablo 2'de toplu olarak gösterilmiştir;

Tablo 2. Toplu Regresyon Analizi Sonuçları

\begin{tabular}{lll}
\hline Yıllar & F değeri & Adj. $\mathbf{R}^{\mathbf{2}}$ \\
\hline $2000-2003$ & 23,560 & 0,505 \\
& $(0,000)^{*}$ & \\
\hline $2006-2009$ & 12,444 & 0,353 \\
& $(0,000)^{*}$ & \\
\hline $2012-2015$ & 5,241 & 0,167 \\
& $(0,000)^{*}$ & \\
\hline
\end{tabular}

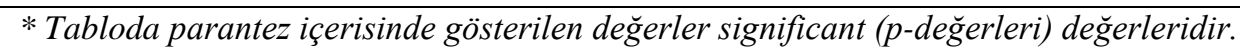

Tablo 1'de sunulan regresyon analizi sonuçlarına göre, 2000-2003 döneminde (konsolidasyon öncesi dönem) bağımsız değişkenlerden sadece karlılık oranının (ROA aranı: net kar/aktif toplamı) hisse senedi getirisini etkileme düzeyinin önemli olduğu görülmektedir. Diğer taraftan, konsolidasyona geçişten sonraki dönemde (2006-2009 dönemi) karlılık oranından ziyade, bağımsız değișkenlerden finansal yapı oranı (kısa vadeli yabancı kaynaklar/toplam aktif oranı) ve likidite oranlarının (cari oran ve asit test oran1) hisse senedi getirisini önemli düzeyde etkilediği görülmektedir. Bu sonuç bize, konsolidasyona geçiş ile birlikte, finansal tablo kullanıcılarından getiri önceliği olan yatırımcılar açısından, finansal yapı ve likidite oranlarının karlılık oranından daha önemli hale geldiğine işaret etmektedir. $\mathrm{Bu}$ çalışmanın yapıldığı son dönem (2012-2015 dönemi) sonuçlarına baktığımızda ise, sadece finansal yapı oranının (kısa vadeli yabancı kaynaklar/toplam aktif oranı) hisse senedi getirisini etkileme düzeyinin önemli olduğu görülmektedir.

Konsolidasyon öncesi dönemde (2000-2003) hisse senedi getirisi ile r2 (toplam borç/öz kaynak oranı), arasında pozitif bir ilişki varken, bu ilişkinin yönü konsolidasyon 
sonrası dönemde (2006-2009) ve bu çalışmanın yapıldığı son dönemde (2012-2015) negatife dönmüştür. Diğer bir ifadeyle, konsolidasyona geçiş ile birlikte toplam borç/öz kaynak oranı ile hisse senedi getirilerini arasındaki ilişki ters yönlü olarak gerçekleşmiştir. Diğer taraftan, konsolidasyon öncesi dönemde (2000-2003 dönemi) hisse senedi getirisi ile asit test oran1 arasındaki negatif ilişki, konsolidasyon sonrası dönemde (2006-2009) ve bu çalışmanın yapıldığı son dönemde (2012-2015) pozitif olarak gerçekleşmiştir. Bu sonuç bize, konsolidasyona geçiş ile birlikte, firmaların asit test oranı ile hisse senedi getirisi arasında aynı yönlü bir ilişkinin varlığını ifade etmektedir. Diğer taraftan, r1 (kısa vadeli yabancı kaynaklar/toplam aktif oranı) , r3 (ROA: net kar/ortalama toplam aktif) ve r4 (Cari Oran: dönen varlıklar/kısa vadeli yabancı kaynaklar) oranları ile hisse senedi getirisi aralarındaki ilişkide dönemler itibariyle herhangi bir değişiklik meydana gelmemiştir.

Konsolidasyon öncesi dönemde (2000-2003) hisse senedi getirileri ile r5 oran1 (Asit Test Oranı: dönen varlıklar-stoklar/kısa vadeli yabancı kaynaklar) arasındaki negatif yönlü ilişki, konsolidasyon sonrası dönemde (2006-2009) ve bu çalışmanın yapıldığı son dönemde (2012-2015) pozitif olarak gerçekleşmiştir. Diğer taraftan, konsolidasyon öncesi dönemde (2000-2003), r1(kısa vadeli yabancı kaynaklar/toplam aktif oranı), r3 (ROA: net kâr/ortalama toplam aktif) ve r4 (Cari Oran: dönen varlıklar/kısa vadeli yabancı kaynaklar) oranlarının hisse senedi getirileri ile arasındaki ilişkinin değişmeyerek konsolidasyon sonrası dönemde (2006-2009) ve bu çalışmanın yapıldığı son dönemde (2012-2015) de aynı şekilde devam etmesi; r2 oranının (toplam borç/öz kaynak oranı) hisse senedi getirileri üzerinde konsolidasyon öncesi dönemde (2000-2003) pozitif yönlü olan etkisinin, konsolidasyon sonrası dönemde (2006-2009) ve bu çalışmanın yapıldığı son dönemde (2012-2015) negatif yönlü olarak gerçekleşmesi, Rasyo Modeli’ndeki bağımsız değişkenlerin (finansal oranlar) bağımlı değişkendeki (hisse senedi getirisi) farklılığı açıklama düzeyinin dönemler itibariyle düşmesine sebep olmuştur. Bu sonuçlar bize, hisse senedi getirilerine finansal yapı oranının (r2) likidite oranına (r5) göre daha fazla etkisinin olduğunu göstermektedir.

Ayrıca, UFRS 10 kapsamında konsolidasyona geçişin firmaların hisse senedi getirisi üzerine etkisini değerlendirmek amacıyla dönemler ikişerli olarak ele alınarak analizler yapılmış ve bağımsız değişken olarak dönem değişkeni de dikkate alınarak dönemlerin karşılaştırılması sağlanmıştır. İkişerli dönemler bazında Rasyo Modeli regresyon analizi sonuçları Tablo 3 'te sunulmuştur;

Tablo 3. İkişerli Dönemler Bazında Rasyo Modeli Regresyon Analizi Sonuçları

\begin{tabular}{|c|c|c|c|c|}
\hline $\begin{array}{l}2000-2003 \text { ve } \\
2006-2009\end{array}$ & \multicolumn{4}{|c|}{$R_{i t+1}=\beta_{0}+\beta_{1}{ }^{*} r 1_{i t}+\beta_{2}{ }^{*} r 2_{i t}+\beta_{3}{ }^{*} r 3_{i t}+\beta_{4}{ }^{*} r 4_{i t}+\beta_{5}{ }^{*} r 5_{i t}+\varepsilon_{i t}$} \\
\hline Değişken & Katsayı & VIF & t değeri & t Sig. \\
\hline$\beta 0$ & 22,897 & & 5,316 & 0,000 \\
\hline Dönem & $-10,595$ & 1,068 & $-3,912$ & 0,000 \\
\hline r1 & $-0,074$ & 1,634 & $-0,772$ & 0,440 \\
\hline r2 & 0,000 & 1,076 & 0,484 & 0,629 \\
\hline r3 & 0,341 & 1,348 & 2,840 & 0,005 \\
\hline $\mathrm{r} 4$ & $-1,351$ & $\begin{array}{l}7,078 \\
\end{array}$ & $-1,477$ & 0,141 \\
\hline
\end{tabular}


Tablo 3 Devamı;

\begin{tabular}{|c|c|c|c|c|}
\hline r5 & 0,609 & 7,043 & 0,531 & 0,596 \\
\hline F Değeri & $\begin{array}{l}5,489 \\
(0,000) *\end{array}$ & & & \\
\hline $\mathbf{R}^{2}$ & 0,088 & & & \\
\hline Adj. $R^{2}$ & 0,072 & & & \\
\hline $\begin{array}{l}\text { 2006-2009 ve } \\
2012-2015\end{array}$ & \multicolumn{4}{|c|}{$R_{i t+1}=\beta_{0}+\beta_{1}{ }^{*} r 1_{i t}+\beta_{2}{ }^{*} r 2_{i t}+\beta_{3}{ }^{*} r 3_{i t}+\beta_{4}{ }^{*} r 4_{i t}+\beta_{5}{ }^{*} r 5_{i t}+\varepsilon_{i t}$} \\
\hline Değişken & Katsayı & VIF & t değeri & t Sig. \\
\hline$\beta 0$ & 16,259 & & 6,099 & 0,000 \\
\hline Dönem & $-4,011$ & 1,066 & $-2,746$ & 0,006 \\
\hline r1 & $-0,235$ & 7,768 & $-3,932$ & 0,000 \\
\hline r2 & $-0,001$ & 1,287 & $-0,178$ & 0,859 \\
\hline r3 & 0,001 & 1,027 & 0,075 & 0,941 \\
\hline $\mathrm{r} 4$ & $-1,619$ & 7,814 & $-1,463$ & 0,145 \\
\hline r5 & 2,166 & 7,336 & 1,636 & 0,103 \\
\hline F Değeri & $\begin{array}{l}6,712 \\
(0,000)^{*}\end{array}$ & & & \\
\hline $\mathbf{R}^{2}$ & 0,108 & & & \\
\hline Adj. $R^{2}$ & 0,092 & & & \\
\hline $\begin{array}{l}\text { 2000-2003 ve } \\
2012-2015\end{array}$ & \multicolumn{4}{|c|}{$R_{i t+1}=\beta_{0}+\beta_{1}^{*} r 1_{i t}+\beta_{2}^{*} r 2_{i t}+\beta_{3}^{*} r 3_{i t}+\beta_{4} * r 4_{i t}+\beta_{5}^{*} r 5_{i t}+\varepsilon_{i t}$} \\
\hline Değişken & Katsayı & VIF & t değeri & t Sig. \\
\hline$\beta 0$ & 29,215 & & 8,096 & 0,000 \\
\hline Dönem & $-16,406$ & 1,047 & $-6,352$ & 0,000 \\
\hline r1 & $-0,198$ & 1,286 & $-2,398$ & 0,017 \\
\hline r2 & 0,000 & 1,080 & 0,406 & 0,685 \\
\hline r3 & 0,010 & 1,007 & 0,362 & 0,718 \\
\hline $\mathrm{r} 4$ & $-1,653$ & 7,413 & $-1,770$ & 0,078 \\
\hline r5 & 0,856 & 7,373 & 0,729 & 0,466 \\
\hline F Değeri & $\begin{array}{l}7,468 \\
(0,000)^{*}\end{array}$ & & & \\
\hline $\mathbf{R}^{2}$ & 0,116 & & & \\
\hline Adj. $R^{2}$ & 0,101 & & & \\
\hline
\end{tabular}

* Tabloda parantez içerisinde gösterilen dĕgerler significant (p-değerleri) dĕgerleridir.

Tablo 3'te dönemlerin ikişerli olarak ve Rasyo Modeli'ne dönem değişkeninin dummy variable (kukla değişken) olarak eklenerek test edilmesini öngören regresyon analiz sonuçları değerlendirildiğinde, ikişerli dönemlerin tümünde hisse senedi getirisi ile dönem değişkeni arasında önemli, fakat negatif bir ilişkinin varlığından söz etmek mümkündür. Bu sonuç bize, 
konsolidasyona geçiş ile firmaların hisse senedi getirisi arasında istatistiksel olarak anlamlı negatif bir ilişkinin olduğunu göstermektedir. Fakat, konsolidasyona geçiş döneminde (20002003 ve 2006-2009) dönem değişkenin etkisi konsolidasyon sonrası dönemlere (2006-2009 ve 2012-2015) göre daha fazla olmuştur. Bu sonuç bize, konsolidasyona geçişin önemli olduğunu, fakat konsolidasyona geçişin hisse senedi getirilerine etkisinin negatif olduğunu göstermektedir. Konsolidasyona geçiş öncesi ve bu çalışmanın yapıldığı son dönemi kapsayan ikişerli dönemde (2000-2003 ve 2012-2015), dönem değişkeni hisse senedi getirisini konsolidasyona geçiş dönemine (2000-2003 ve 2006-2009) göre daha fazla etkilemiştir. Diğer bir ifadeyle, dönem uzadıkça konsolidasyona geçişin hisse senedi getirileri üzerindeki etkisinde artış meydana gelmiştir.

\section{SONUÇ}

Literatürde UFRS 10 kapsamında konsolidasyona geçişin firmaların hisse senedi getirisi üzerindeki etkisine yönelik yapılan çalışmalarda hem olumlu hem de olumsuz sonuçlar ortaya çıkmıştır. Literatürdeki mevcut çalışma ve tartışmalara katkı sağlamak amacıyla gerçekleştirilen bu çalışmada, UFRS 10 kapsamında konsolidasyona geçişin firmaların hisse senedi getirisi üzerindeki etkisi analiz edilmiştir.

Araştırmanın bulgularına göre, firmaların hisse senedi getirileri ile finansal oranlar arasındaki ilişkinin belirlenmesine yönelik kullanılan Rasyo Modelleri'nde, konsolidasyona geçiş ile birlikte bazı finansal oranlar ile hisse senedi getirileri arasında meydana gelen değişiklik $\mathrm{H}_{0}$ hipotezini reddeder niteliktedir.

Sonuç olarak, BIST’te işlem gören firmaların hisse senedi getirileri ile finansal oranları arasındaki ilişkiyi analiz eden araştırma bulguları, konsolidasyona geçiş ile birlikte bazı oranların (finansal yap1 oranı: r2) hisse senedi getirileri üzerindeki etkisinin (negatif), diğer bazı oranların etkisine (pozitif) göre (likidite oranı: r5) daha fazla olduğunu göstermektedir. Bu sonuç, konsolidasyon öncesi dönemde hazırlanmış finansal tablolardan elde edilen finansal oranların, konsolidasyon sonrası dönemdeki finansal oranlara göre firmaların hisse senedi getirilerindeki değişimi açıklama düzeyine daha fazla katk1 sağlamasına sebep olmuştur. Bu sebeple, bu çalışmanın sonuçları konsolidasyona geçişin firmaların hisse senedi getirisi üzerindeki etkisinin oranlar bazında farklılık gösterdiğini ifade etmektedir. $\mathrm{Bu}$ açıdan, bu sonuç literatürdeki bazı çalışma sonuçları ile benzerlik göstermesine rağmen, bazı çalışma sonuçları ile de farklılık göstermektedir (Hung ve Subramanyam, 2007; Callao vd., 2007; Ataman ve Özden, 2009; Gastón vd., 2010; Blanchette vd., 2011; Büyükşalvarcı ve Uyar, 2012; Sultanoğlu, 2014; vb. gibi).

Türkiye'de konsolidasyonun son 12 yıldır uygulanıyor olmasından dolayı, konuyla ilgili yapılan çalışma sayısı oldukça sınırlıdır. Bu sebeple, konu ile ilgili olarak gelecekte yapılacak çalışmalarda, yatırımcıların hisse senedi getirilerini değerlendirirken dikkate aldıkları ya da değişen koşullara göre dikkate alabilecekleri diğer faktörlerin de kullanılması, konunun yaygınlaşmasını sağlayacak ve konuya farklı bir bakış açısı kazandıracaktır. 


\section{KAYNAKLAR}

Akgün, Ali İhsan (2012), "Muhasebenin Uluslararası Harmonizasyonu Ve İlke Bazlı Muhasebe Anlayışına Yöneliş", Yönetim ve Ekonomi, 19(2), ss. 1-16.

Ataman, Başak - Özden A., Evrim (2009), “Tek Düzen Hesap Planına Göre Hazırlanan Finansal Tabloların UFRS'ye Uyarlanması Ve Rasyo Yöntemi İle Analizi”, Muhasebe ve Finansman Dergisi, (44), ss. 59-73.

Bayrakdaroğlu, Ali (2012), "Performans Ölçütlerinin Hisse Senedi Getirilerini Açıklayabilme Gücü Üzerine Ampirik Bir Çalışma”, Muhasebe ve Finansman Dergisi, (53), ss. 139158.

Blanchette, Michel - Racicot François-Éric - Girard Jean-Yves (2011), “The Effect Of IFRS On Financial Ratios: Early Evidence In Canada”, Certified General Accountants Association of Canada, pp. 1-57.

Büyükşalvarcı, Ahmet - Uyar Süleyman (2012), "Farklı Muhasebe Düzenlemelerine Göre Hazırlanan Mali Tablolardan Elde Edilen Finansal Oranlar İle Şirketlerin Hisse Senedi Getirileri Ve Piyasa Değerleri Arasındaki İlişki”, Muhasebe ve Finansman Dergisi, 53, ss. 25-48.

Callao, Susana - Jarne José I. - Laínez José A. (2007), “Adoption Of IFRS In Spain: Effect On The Comparability And Relevance Of Financial Reporting”, Journal of International Accounting, Auditing and Taxation, 16(2), pp. 148-178.

Hung, Mingyi - Subramanyam K. R. (2007), "Financial Statement Effects Of Adopting International Accounting Standards: The Case Of Germany”, Review of Accounting Studies, 12(4), pp. 623-657.

Gastón, Susana Callao - García, Cristina Ferrer - Jarne, José Ignacio Jarne - Gadea, José Antonio Laínez (2010), "IFRS Adoption In Spain And The United Kingdom: Effects On Accounting Numbers And Relevance”, Advances in Accounting, Incorporating Advances in International Accounting, 26, pp. 304-313.

Sultanoğlu, Banu (2014), “UFRS'nin Borsa İstanbul'daki Şirketlerin Finansal Tabloları Üzerindeki Etkisi: Finansal Bilginin İhtiyaca Uygunluğu Ve Finansal Tablolar Analizi”, Yayınlanmamış doktora tezi, Başkent Üniversitesi, Ankara. 